\title{
Efektifitas Em-4 (Effective Microorganism-4) dalam Menurunkan NH3 (Amoniak) dan TSS (Total Suspended Solid) Limbah Cair BBKPM Surakarta
}

\section{Effectiveness of EM-4 (Effective Microorganism-4) in Reducing NH3 (Ammoniac) and TSS (Total Suspended Solid) Waste Of BBKPM Liquid Waste Surakarta}

\author{
Triyanta $^{1}$, Nine Elissa Maharani ${ }^{2}$ \\ Program Studi Kesehatan Masyarakat \\ Universitas Veteran Bangun Nusantara \\ Email :Elissapanjimomo@gmail..com
}

\begin{abstract}
Background: The Surakarta Center for Community Lung Health is the UPT of the Indonesian Ministry of Health which in its service process produces wastewater. The results of the NH3 parameter check still show results above the threshold determined by Central Java Provincial Regulation No. 5 of 2012 which is $0.5 \mathrm{mg} / \mathrm{lt}$ while the standard is $0.1 \mathrm{mg} / \mathrm{lt}$. TSS examination results are also still above the threshold determined by Central Java Perda No. 5 of 2012 which is 38$43 \mathrm{mg} / \mathrm{lt}$ while the standard is $30 \mathrm{mg} / \mathrm{lt}$.

Research Methods: This research is a pure experiment with a pretest-posttest group design. The population of this study is the wastewater wastewater WWKPM Surakarta. The sample of this study were 15 samples of liquid waste. The independent variable is EM-4 and the dependent variable is NH3 and TSS. Analysis of the data used is descriptive analysis).

Results: The results showed that the Ammonia (NH3) level of BBKPM Surakarta wastewater prior to the EM-4 administration treatment was $1.03 \mathrm{mg} / \mathrm{lt}$, the total Suspended Solid (TSS) liquid waste before the EM-4 administration treatment was $59 \mathrm{mg} / \mathrm{lt}$, and Ammonia (NH3) levels of liquid waste after EM-4 treatment is $<0.002 \mathrm{mg} / \mathrm{lt}$ either with the addition of $10 \mathrm{ml}, 20 \mathrm{ml}$ or $30 \mathrm{ml} \mathrm{EM}-4$. Total levels of Suspended Solid (TSS) Surakarta BBKPM liquid waste after the treatment of EM-4

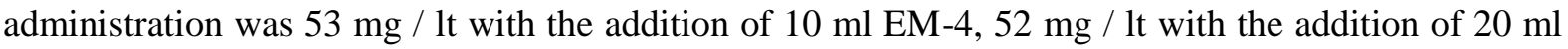
EM-4, $51 \mathrm{mg} / \mathrm{lt}$ with the addition EM-4 as much as $30 \mathrm{ml}$.

Conclusion: The results showed that the administration of EM-4 was effective in reducing NH3 levels and was not yet effective in reducing TSS Surakarta BBKPM liquid waste. The most effective EM-4 dose for reducing NH3 and TSS levels in liquid waste is $10 \mathrm{ml}$.

Keywords: Liquid waste, NH3 and TSS levels, EM-4 administration
\end{abstract}

\begin{abstract}
ABSTRAK
Latar Belakang: Balai Besar Kesehatan Paru Masyarakat Surakarta merupakan UPT Kementerian kesehatan RI yang dalam proses pelayanannya menghasilkan air limbah. Hasil pemeriksaan parameter NH3 masih menunjukkan hasil diatas ambang batas yang ditentukan Perda Prop Jateng No. 5 Tahun 2012 yaitu $0,5 \mathrm{mg} / \mathrm{lt}$ sedangkan standarnya $0,1 \mathrm{mg} / \mathrm{lt}$. Hasil pemeriksaan TSS juga masih diatas ambang batas yang ditentukan Perda Prop Jateng No. 5 Tahun 2012 yaitu 38$43 \mathrm{mg} / \mathrm{lt}$ sedangkan standarnya $30 \mathrm{mg} / \mathrm{lt}$.

Metode Penelitian: Jenis penelitian ini adalah eksperimen murni dengan rancangan pretest-postest group. Populasi penelitian ini adalah limbah cair IPAL BBKPM Surakarta. Sampel penelitian ini sebanyak 15 sampel limbah cair. Variabel bebas yaitu EM-4 dan variabel terikat yaitu NH3 dan TSS. Analisa data yang digunakan adalah analisa deskriptif).

Hasil Penelitian: Hasil penelitian didapatkan hasil kadar Amoniak (NH3) limbah cair BBKPM Surakarta sebelum perlakuan pemberiaan EM-4 sebesar 1,03 mg/lt, kadar Total
\end{abstract}


Suspended Solid (TSS) limbah cair sebelum perlakuan pemberiaan EM-4 sebesar $59 \mathrm{mg} / \mathrm{lt}$, dan kadar Amoniak (NH3) limbah cair sesudah perlakuan pemberiaan EM-4 sebesar < 0,002 mg/lt baik dengan penambahan EM-4 sebesar $10 \mathrm{ml}, 20 \mathrm{ml}$ maupun $30 \mathrm{ml}$. Kadar Total Suspended Solid (TSS) limbah cair BBKPM Surakarta sesudah perlakuan pemberiaan EM-4 sebesar $53 \mathrm{mg} / \mathrm{lt}$ dengan penambahan EM-4 sebanyak $10 \mathrm{ml}, 52 \mathrm{mg} / \mathrm{lt}$ dengan penambahan EM-4 sebanyak $20 \mathrm{ml}$, $51 \mathrm{mg} / \mathrm{lt}$ dengan penambahan EM-4 sebanyak $30 \mathrm{ml}$.

Kesimpulan: Hasil penelitian menunjukkan bahwa pemberian EM-4 efektif menurunkan kadar NH3 dan belum efektif untuk menurunkan TSS limbah cair BBKPM Surakarta. Dosis EM-4 yang paling efektif untuk penurunan kadar NH3 dan TSS limbah cair adalah $10 \mathrm{ml}$.

Kata Kunci : Limbah cair, kadar NH3 dan TSS, pemberian EM-4

\section{PENDAHULUAN}

Pengolahan limbah BBKPM adalah bagian dari kegiatan penyehatan lingkungan yang bertujuan untuk melindungi masyarkat dari bahaya pencemaran lingkungan yang bersumber dari limbah. Efek negatif yang mungkin timbul sebagai akibat dari kondisi lingkungan yang tidak sehat karena pengolahan limbah yang kurang sempurna, diantaranya adanya bakteri patogen yang menyebabkan penyakit. Air limbah memiliki potensi yang berbahaya bagi kesehatan, maka perlu pengolahan air limbah yang baik dan benar, yaitu dengan adanya instalasi pengolahan air limbah. Oleh karena itu pembangunan sarana pelayanan kesehatan harus disertai dengan pengawasan, pemantauan, dan perhatian terhadap limbah yang dihasilkan. Limbah yang dihasilkan dari sarana pelayanan kesehatan dapat berupa limbah padat, cair, dan gas yang bersifat infeksius maupun non infeksius.

Kadar zat organik dan anorganik yang tinggi dalam air limbah yang mengalami dekomposisi menghasilkan menghasilkan produk sampingan yang sangat toksik yaitu amoniak (NH3). Disamping itu juga dapat menyebabkan tingginya Total Suspended Solid (TSS) yaitu padatan yang menyebabkan kekeruhan air, tidak terlarut dan tidak dapat mengendap langsung.

Amoniak dan bahan yang tersuspensi maupun yang terlarut dalam air limbah yang sangat mengganggu lingkungan ini, dapat diuraiakan oleh mikroorganisme pengurai. Mikroorganisme pengurai ini sekarang sudah dapat dikembangbiakan melalui pembuatan sebuah kultur kelompok mikroorganisme, yang dipelopori oleh Prof. Dr. Teruo Higa dari University of The Ryukus Okinawa Jepang yang disebut Effective Microorganisms yang disingkat EM. Nama EM tersebut ada berbagai macam dengan kandungan mikroorganisme yang berbeda. EM1 yang berupa media padat berbentuk butiran yang mengandung $90 \%$ actinomicetes. Berfungsi untuk mempercepat proses pembentukan kompos dalam tanah. EM2 terdiri dari 80 species yang disusun berdasarkan perbandingan tertentu.Berbentuk kultur dalam kaldu ikan dengan $\mathrm{pH}$ 8,5. dalam tanah mengeluarkan antibiotik untuk menekan patogen. EM3 terdiri dari 95\% bakteri fotosintetik dengan $\mathrm{pH} 8,5$ dalam kaldu ikan yang berfungsi membantu tugas EM2. Sakarida dan asam amino disintesa oleh bakteri fotosintetik sehingga secara langsung dapat diserap tanaman. EM4 terdiri dari 95\% lactobacillus yang berfungsi menguraikan bahan organik tanpa menimbulkan panas tinggi karena mikroorganisme anaerob bekerja dengan kekuatan enzim. EM5 berupa pestisida organik 
Dari hasil survei awal limbah cair di BBKPM Surakarta didapatkan hasil bahwa pemeriksaan pamameter NH3 meskipun air limbah sudah diolah di IPAL masih menunjukkan hasil diatas ambang batas yang ditentukan Perda Prop Jateng No. 5 Tahun 2012 yaitu $0,5 \mathrm{mg} / \mathrm{lt}$ sedangkan standarnya $0,1 \mathrm{mg} / \mathrm{lt}$. Hasil pemeriksaan TSS juga masih diatas ambang batas yang ditentukan Perda Prop Jateng No. 5 Tahun 2012 yaitu 38-43 $\mathrm{mg} / \mathrm{lt}$ sedangkan standarnya $30 \mathrm{mg} / \mathrm{lt}$.

Berdasarkan hasil survei awal tersebut, peneliti ingin melakukan penelitian lebih lanjut tentang keefektifan EM-4 (effective microorganism-4) dalam menurunkan NH3 (Amoniak) dan TSS (Total Suspended Solid) limbah cair BBKPM Surakarta

\section{METODE}

Jenis penelitian ini adalah penelitian penjelasan (Explanatory atau Confirm Research) yang termasuk dalam kelompok Eksperimen Murni (True Experiment) di IPAL BBKPM Surakarta bulan Juni-September 2018.

Populasi dalam penelitian ini limbah cair dari IPAL BBKPM Surakarta. Sampel pada penelitian ini air limbah BBKPM Surakarta sebanyak 15 sampel. Teknik samplingnya, non random sampling (purposive sampling). Analisa data yang digunakan adalah analisis dengan cara deskriptif.

\section{HASIL DAN PEMBAHASAN}

Berdasarkan hasil pemeriksaan efektifitas EM-4 (Effective Microorganism-4) dalam menurunkan NH3 (amoniak) dan TSS (total suspended solid) limbah cair BBKPM Surakarta diperoleh hasil sebagai berikut :

\section{Tabel 1. Kondisi pH Sebelum dan Sesudah Perlakuan}

\begin{tabular}{llccc}
\hline $\begin{array}{c}\text { Pengula } \\
\text { ngan }\end{array}$ & $\begin{array}{c}\text { Sebelum } \\
\text { Perlakuan }\end{array}$ & $10 \mathrm{ml}$ & $\begin{array}{c}\text { Sesudah Perlakuan Penambahan EM-4 } \\
20 \mathrm{ml}\end{array}$ & $30 \mathrm{ml}$ \\
\hline 1 & 7,16 & 7,16 & 7,16 & 7,16 \\
2 & 7,16 & 7,16 & 7,16 & 7,16 \\
3 & 7,16 & 7,16 & 7,16 & 7,16 \\
Median & 7,16 & 7,16 & 7,16 & 7,16 \\
Baku & & $6,0-9,0$ & \\
Mutu & & & \\
\hline \multicolumn{5}{l}{ Sumber : } \\
\hline
\end{tabular}

\section{Tabel 2. Kondisi Suhu Sebelum dan Sesudah Perlakuan}

\begin{tabular}{|c|c|c|c|c|}
\hline \multirow{2}{*}{$\begin{array}{c}\text { Pengula } \\
\text { ngan }\end{array}$} & \multirow[t]{2}{*}{ Sebelum } & \multicolumn{3}{|c|}{ Sesudah Perlakuan Penambahan EM-4 } \\
\hline & & $10 \mathrm{ml}$ & $20 \mathrm{ml}$ & $30 \mathrm{ml}$ \\
\hline 1 & $26^{\circ} \mathrm{C}$ & $26^{\circ} \mathrm{C}$ & $26^{\circ} \mathrm{C}$ & $26^{\circ} \mathrm{C}$ \\
\hline 2 & $26^{\circ} \mathrm{C}$ & $26^{\circ} \mathrm{C}$ & $26^{\circ} \mathrm{C}$ & $26^{\circ} \mathrm{C}$ \\
\hline 3 & $26^{\circ} \mathrm{C}$ & $26^{\circ} \mathrm{C}$ & $26^{\circ} \mathrm{C}$ & $26^{\circ} \mathrm{C}$ \\
\hline Median & $26^{\circ} \mathrm{C}$ & $26^{\circ} \mathrm{C}$ & $26^{\circ} \mathrm{C}$ & $26^{\circ} \mathrm{C}$ \\
\hline Baku & & & $30^{c}$ & \\
\hline Mutu & & & & \\
\hline
\end{tabular}


Tabel 3. Kadar NH3 Sebelum dan Sesudah Perlakuan

\begin{tabular}{lcccc}
\hline $\begin{array}{c}\text { Pengula } \\
\text { ngan }\end{array}$ & Sebelum & \multicolumn{3}{c}{ Sesudah Perlakuan Penambahan EM-4 } \\
\hline 1 & & $10 \mathrm{ml}$ & $20 \mathrm{ml}$ & $30 \mathrm{ml}$ \\
2 & 1,03 & $<0,002$ & $<0,002$ & $<0,002$ \\
3 & 1,05 & $<0,002$ & $<0,002$ & $<0,002$ \\
Median & 1,00 & $<0,002$ & $<0,002$ & $<0,002$ \\
Baku & 1,03 & $<0,002$ & $<0,002$ & $<0,002$ \\
Mutu & & & $0,1 \mathrm{mg} / \mathrm{lt}$ & \\
\hline
\end{tabular}

Sumber : Data primer yang diolah

Tabel 4. Kadar TSS Sebelum dan Sesudah Perlakuan

\begin{tabular}{lcccc}
\hline $\begin{array}{c}\text { Pengula } \\
\text { ngan }\end{array}$ & Sebelum & \multicolumn{3}{c}{ Sesudah Perlakuan Penambahan EM-4 } \\
\hline 1 & & $10 \mathrm{ml}$ & $20 \mathrm{ml}$ & $30 \mathrm{ml}$ \\
2 & 59 & 53 & 52 & 51 \\
3 & 59 & 86 & 78 & 69 \\
Median & 59 & 42 & 37 & 36 \\
Baku & 59 & 53 & 52 & 51 \\
Mutu & & & $30 \mathrm{mg} / \mathrm{lt}$ & \\
\hline
\end{tabular}

Sumber : Data primer yang diolah

Hasil tersebut dapat dijelaskan sebagai berikut:

1. $\mathrm{pH}$ Sebelum dan Sesudah Perlakuan

Hasil pengukuran $\mathrm{pH}$ sebelum dan sesudah perlakuan dengan pemberian EM-4 pada limbah cair menunjukkan bahwa kondisi $\mathrm{pH}$ tidak terdapat perbedaan yaitu 7,16 . Hal tersebut menunjukkan bahwa pemberian EM-4 berbagai dosis tidak mempengaruhi $\mathrm{pH}$ pada limbah cair. $\mathrm{pH}$ pada limbah cair yang optimum sebesar 6-8 karena $\mathrm{pH}$ yang terlalu tinggi lebih dari 8 akan menghambat aktivitas mikroorganisme, sedangkan $\mathrm{pH}$ dibawah 6 akan mengakibatkan pertumbuhan jamur dan terjadi persaingan dengan bakteri dalam metabolisme materi organik (Waluyo, 2009). Menurut Jenni dan Rahayu (2007) jika pH kurang dari 6 dan lebih dari 8 menyebabkan mikroorganisme pada EM-4 tidak aktif atau bahkan mati. Hasil pengukuran $\mathrm{pH}$ tersebut sesuai dengan Peraturan Menteri Lingkungan Hidup Nomor 5 tahun 2014 tentang baku mutu limbah cair yaitu 6 - 9.

2. Suhu Sebelum dan Sesudah Perlakuan

Hasil pengukuran suhu sebelum dan sesudah perlakuan dengan pemberian EM-4 pada limbah cair menunjukkan bahwa kondisi suhu tidak terdapat perbedaan yaitu $26^{\circ} \mathrm{C}$. Hal itu menunjukkan bahwa pemberian EM-4 berbagai dosis tidak mempengaruhi Suhu pada limbah cair. Suhu pada limbah cair yang optimum sebesar $25^{\circ} \mathrm{C}-30^{\circ} \mathrm{C}$, suhu yang terlalu rendah atau terlalu tinggi akan merusak proses dengan mencegah aktivitas mikroorganisme yang terdapat pada EM-4 (Saraswati, 2010). Hasil pengukuran suhu tersebut sesuai dengan Peraturan Daerah Provinsi Jawa Tengah Nomor 5 tahun 2012 tentang baku mutu limbah cair dengan kadar maksimal sebesar $38^{\circ} \mathrm{C}$.

3. Kadar TSS Limbah Cair

Berdasarkan hasil pemeriksaan laboratorium kadar TSS limbah cair dengan pemberian EM-4 dosis $10 \mathrm{ml}, 20 \mathrm{ml}$, dan $30 \mathrm{ml}$ dengan pengulangan sebanyak 3 kali mengalami penurunan masing-masing sebesar $53 \mathrm{mg} / \mathrm{lt}, 52 \mathrm{mg} / \mathrm{lt}, 51 \mathrm{mg} / \mathrm{lt} . \mathrm{mg} / \mathrm{l}$. Kadar 
TSS tersebut masih diatas nilai ambang batas baku mutu limbah cair untuk kegiatan RS yaitu 30 mg/l (Perda Propinsi Jawa Tengah Nomor 5 tahun 2012).

\section{Kadar NH3 Limbah Cair}

Berdasarkan hasil pemeriksaan laboratorium kadar NH3 limbah cair dengan pemberian EM-4 dosis $10 \mathrm{ml}, 20 \mathrm{ml}$, dan $30 \mathrm{ml}$ dengan pengulangan sebanyak 3 kali mengalami penurunan sebesar $<0,002 \mathrm{mg} / \mathrm{lt}$. Kadar NH3 tersebut sudah dibawah nilai ambang batas baku mutu limbah cair untuk kegiatan RS yaitu 0,1 mg/lt (Perda Propinsi Jawa Tengah Nomor 5 tahun 2012).

Terjadinya penurunan kadar TSS dan NH3 pada limbah cair menandakan adanya aktivitas mikroorganisme pada EM-4 yang mampu mendegradasi bahan-bahan pencemar yang terkandung dalam air limbah. Adanya proses pemecahan atau penguraian senyawa organik menjadi senyawa yang lebih sederhana secara tidak langsung dapat menurunkan nilai TSS dan NH3. Bakteri Lactobacillus sp yang terdapat dalam EM-4 mampu memfermentasikan bahan organik limbah cair menjadi senyawa asam laktat untuk mempercepat perombakan bahan organik (Isa, 2008).

Selain itu adanya kerjasama asam laktat (Lactobacillus $s p$ ) dengan jamur fermentasi (Saccharomyces sp) yang terkandung dalam EM-4 dalam memfermentasikan bahan organik menjadi senyawa-senyawa organik yang lebih sederhana sehingga cenderung lebih cepat dibanding dengan proses penguraian senyawa organik alamiah dalam limbah cair. Adanya penguraian senyawa organik menjadi senyawa yang lebih sederhana secara tidak langsung dapat menurunkan kadar TSS dan NH3 (Avlenda, 2009).

Menurut Setiawan (2010) salah satu manfaat dai EM-4 dapat menurunkan kadar TSS dan NH3 pada limbah cair. Hal ini terbukti bahwa dengan pemberian EM-4 berbagai dosis mampu menurunkan kadar TSS dan NH3 pada limbah dan semakin besar dosis EM-4 yang ditambahkan pada limbah cair maka semakin besar pula penurunan kadar TSS maupun amoniak dalam limbah cair BBKPM Surakarta.

5. Dosis EM-4 yang Efektif dalam Menurunkan Kadar TSS dan NH3 Limbah Cair BBKPM Surakarta.

Hasil Pemeriksaan Laboratorium didapatkan dosis yang paling efektif menurunkan kadar NH3 dan TSS pada limbah cair BBKPM Surakarta adalah $10 \mathrm{ml}$, dimana dengan volume EM-4 yang dibutuhkan yang paling kecil tetapi penurunannya sangat efektif dibanding dengan penambahan $20 \mathrm{ml}$ dan $30 \mathrm{ml}$. Dari sisi biaya pengadaan EM-4 dengan penambahan $10 \mathrm{ml}$ saja sudah efektif untuk menurunkan TSS maupun NH3 maka penghematan biaya dapat terjadi.

\section{KESIMPULAN}

Berdasarkan hasil penelitian yang telah diraikan pada pembahasan terdahulu dapat diambil kesimpulan sebagai berikut :

1. Kadar Amoniak (NH3) limbah cair BBKPM Surakarta sebelum perlakuan pemberiaan EM-4 sebesar 1,03 mg/lt.

2. Kadar Total Suspended Solid (TSS) limbah cair BBKPM Surakarta sebelum perlakuan pemberiaan EM-4 sebesar $59 \mathrm{mg} / \mathrm{lt}$.

3. Kadar Amoniak (NH3) limbah cair BBKPM Surakarta sesudah perlakuan pemberiaan EM-4 sebesar < 0,002 mg/lt baik dengan penambahan EM-4 sebesar $10 \mathrm{ml}, 20 \mathrm{ml}$ maupun $30 \mathrm{ml}$.

4. Kadar Total Suspended Solid (TSS) limbah cair BBKPM Surakarta sesudah perlakuan pemberiaan EM-4 sebesar $53 \mathrm{mg} / \mathrm{lt}$ dengan penambahan EM-4 sebanyak $10 \mathrm{ml}, 52$ 
mg/lt dengan penambahan EM-4 sebanyak $20 \mathrm{ml}, 51 \mathrm{mg} / \mathrm{lt}$ dengan penambahan EM-4 sebanyak $30 \mathrm{ml}$.

6. Pemberian EM-4 efektif menurunkan kadar NH3 dan belum efektif untuk menurunkan TSS limbah cair BBKPM Surakarta. Dosis EM-4 yang paling efektif untuk penurunan kadar NH3 dan TSS limbah cair adalah $10 \mathrm{ml}$

\section{SARAN}

1. Bagi Peneliti Lain

Menambah dosis EM-4 (Effective Microorganism-4) sampai nilai TSS tidak melebihi baku mutu yaitu $30 \mathrm{mg} / \mathrm{l}$ dan mencari dosis yang optimal untuk menurunkan TSS.

2. Bagi Instansi Kesehatan

Dari instasi kesehatan dapat memberikan penyuluhan atau pengarahan terkait pengolahan limbah agar limbah dapat diolah terlebih dahulu sehingga tidak mencemari lingkungan.

3. Bagi BBKPM Surakarta

Pengolahan air limbah menggunakan EM-4 (Effective Microorganism-4) bisa dijadikan referensi untuk mengatasi pencemaran air limbah yang memiliki kandungan NH3 dan TSS yang tinggi.

\section{DAFTAR PUSTAKA}

Anonim. 2009. Laboratorium Pengujian Limbah dan Lingkungan dan Aneka Komoditi. Semarang : Badan Penelitian dan Pengembangan dan Perdagangan

Asmadi, Suharno. 2012. Dasar-dasar Teknologi pengolahan Air Limbah. Yogyakarta : Gosyen Publishing

Chandra, Budiman. 2014. Pengantar Kesehatan Lingkungan. Jakarta : ECG

Fitria Y. 2008. Pembuatan Pupuk Organik Cair dari Limbah Cair Perikanan Menggunakan Asam Asetat dan EM4 (Effective Microorganism4) .(Online).(http://journal.ubb.ac.id/index.php/aquatic/issue/download/32/26, diakses 14 Oktober 2017)

Ginting P. 2007. Sistem Pengelolaan Lingkungan dan Limbah . Jakarta : Yrama Widya

Hadi A. 2015. Prinsip Pengelolaan Pengambilan Sampel Lingkungan. Jakarta : Gramedia Pustaka Utama

Mahida, UN. 2004. Pencemaran Air dan Pemanfaatan limbah . Jakarta: Rajawali

Notoatmodjo, Soekidjo. 2012. Metodologi Penelitian Kesehatan. Jakarta :Rineka Cipta

Peraturan Daerah Provinsi Jawa Tengah Nomor 5 Tahun 2012 tentang Baku Mutu Limbah Cair untuk Kegiatan dan Tekstil. 2012. Semarang

Peraturan Menteri Lingkungan Hidup Nomor 5 Tahun 2014 tentang Baku Mutu Air Limbah. 2014. Jakarta

Raharjo, M. 2004. Manajemen Laboratorium Kesehatan Lingkungan. Jurnal. Semarang : Fakultas Kesehatan Masyarakat Peminatan Kesehatan Lingkungan Universitas Diponegoro

Setiawan, BS. 2010. Membuat Pupuk Kandang secara Cepat. Depok : Penebar Swadaya

Sugiharto. 2008. Dasar-dasar Pengelolaan Air Limbah. UI-Press. Jakarta 
Jurnal Ilmu Kesehatan Masyarakat Berkala (2019); (1) 1: 34-40

Suharto. 2010. Limbah Kimia dalam Pencemaran Air dan Udara. Yogyakarta : Andi Offset Suharto. 2011. Limbah Kimia dalam Pencemaran Air dan Udara. Yogyakarta : Andi Offset Sumantri, Arif. 2013. Kesehatan Lingkungan. Jakarta: Kencana Prenada Media Group

Undang-undang Republik Indonesia Nomor 32 Tahun 2009 tentang Perlindungan dan pengelolaan Lingkungan Hidup. 2009. Jakarta

Wardhana, W. A. 2007. Dampak Pencemaran Lingkungan. Yogyakarta : Andi 